\title{
Сорбционно-хроматографическая очистка $\alpha$-амилазы Bacillus subtilis на сверхсшитых полистирольных сорбентах
}

\author{
Красовицкая И.А., Глазова Н.В., Котова Н.В. \\ Санкт-Петербургская государственная химико-фармацевтическая академия, Санкт-Петербург
}

Поступила в редакцию 7.04.2017 г.

В работе представлены результаты экспериментов по изучению процесса сорбции $\alpha$-амилазы Bacillus subtilis на сверхсшитых полистирольных сорбентах в статических и динамических условиях. Показана возможность создания обратимо-диссоциирующего комплекса, сочетающего свойства ферментного препарата и энтеросорбента.

Ключевые слова: $\alpha$-амилаза, сорбенты, сверхсшитый полистирол, иммобилизация

\section{Adsorption chromatographic purification of a-amylase Bacillus subtilis on super-cross-linked polystyrene sorbents}

\author{
Krasovitskaya I.A., Glazova N.V., Kotova N.V. \\ St. Petersburg State Chemical Pharmaceutical Academy, St. Petersburg
}

The paper presents the results of studying the process of sorption of Bacillus subtilis $\alpha$-amylase on super-cross-linked polystyrene sorbents MN-200, MN-202 (non-ionic) and MN-500 (sulfocathionite). We are considering the possibility of obtaining a reversible-dissociating complex of $\alpha$-amylase with these sorbents. As a raw material for the obtaining of $\alpha$-amylase a technical enzyme preparation amylosubtilin G3X prepared by fermentation of Bacillus subtilis was used.

Optimal conditions of the process of sorption of $\alpha$-amylase on the sorbents studied were selected. The sorption isotherms of $\alpha$-amylase on the MN-200, MN-202 and MN-500 sorbents have the BET isotherm form, which indicates the orderliness of the sorption centers and the statistical distribution of the protein molecules on the sorbent grain. The highest selectivity is possessed by sulfonate cation exchanger MN-500 $\left(\mathrm{K}_{\mathrm{d}}=169 \pm 0.5 \mathrm{ml} / \mathrm{g}\right)$. The eluent for desorption of $\alpha$-amylase was selected: an ammonia solution $(\mathrm{pH} 10-11)$ for $\mathrm{MN}-500$ and an ammonia solution ( $\mathrm{pH} 10-11$ ) with the addition of an organic solvent (ethanol) for MN200 and $\mathrm{MN}-202$.

The kinetic-dynamic analysis of the $\alpha$-amylase sorption process on the MN-200, MN-202 and MN500 sorbents according to the regularization parameter $\lambda$ showed that the regular regime is achieved only by sorption on the sulfonate cation exchanger MN-500 $(\lambda=0.44)$. For MN-500, the highest yield at the desorption stage of $\alpha$-amylase was obtained, and the concentrating effect was observed.

Thus, MN-500 sulfonate cation exchanger can be recommended for preliminary chromatographic purification of Bacillus subtilis $\alpha$-amylase in the production of a complex preparation combining the properties of the enzyme preparation and the enterosorbent.

Keywords: $\alpha$-amylase, sorbents, super-cross-linked polystyrene, immobilization

\section{Введение}

В настоящее время в медицинской практике широко применяются гидролитические ферменты для лечения заболеваний, связанных с нарушением обмена ве- 
ществ, вызванным ферментативной недостаточностью [1-3]. В частности, $\alpha$-амилаза используется в заместительной энзимотерапии для лечения амилазной недостаточности и желудочно-кишечных заболеваний. Источником $\alpha$-амилазы является технический ферментный препарат амилосубтилин, получаемый ферментацией Bacillus subtilis. Амилосубтилин содержит большое количество примесей, поэтому в процессе получения лекарственного препарата важное значение имеет стадия выделения и очистки $\alpha$-амилазы. Одним из наиболее распространённых методов является хроматографическая очистка.

Сорбенты на основе сверхсшитого полистирола (Стиросорбы) были разработаны В. А. Даванковым и М. П. Цюрупой в начале 70-х годов [4]. Для данного вида сорбентов характерна высокая сорбционная ёмкость, при этом они обладают способностью поглощать разнообразные веществ из водных и органических сред. Стиросорбы можно применять в адсорбционной, гельпроникающей хроматографии, гемосорбции [5]. Эти особенности позволяют рассматривать сорбенты на основе сверхсшитого полистирола в качестве перспективного сорбционного материала для очистки $\alpha$-амилазы.

Очищенная $\alpha$-амилаза входит в состав различных фармацевтических композиций. Применение нативной $\alpha$-амилазы затрудняется ввиду её инактивации при низких значениях $\mathrm{pH}$ [6]. Актуальным является получение стабильной лекарственной формы, устойчивой в кислой среде желудка и проявляющей свою активность в кишечнике. Наиболее распространёнными сейчас являются капсулированные или покрытые оболочкой лекарственные формы ферментов. Однако такие препараты имеют ряд недостатков, например, невозможность применения для лечения грудных детей и ослабленных больных, не способных осуществлять глотательные движения [7].

Целью данной работы являлось исследование сорбционной очистки $\alpha$ амилазы Bacillus subtilis на сверхсшитых полистирольных сорбентах различного типа для создания комплексного препарата для лечения заболеваний ЖКТ.

Помимо хроматографической очистки, рассматривается возможность получения обратимо-диссоциирующего комплекса $\alpha$-амилазы с данными сорбентами. Подобные исследования проводились нами ранее с использованием в качестве носителей карбоксильных катионообменников [8]. На основе полученного комплекса можно создать лекарственную форму, представляющую собой легкораспадающиеся таблетки, более удобную для применения в вышеописанных случаях [7]. Отдельно стоит отметить возможность применения сорбентов на основе сверхсшитого полистирола в качестве энтеросорбентов [9]. Благодаря этому свойству потенциальный препарат $\alpha$-амилазы, иммобилизованной на Стиросорбе, приобретает дополнительное положительное качество.

\section{Эксперимент}

Объектами исследования являлись неионогенные сорбенты MN-200 и MN202 и сульфокатионообменник MN-500 (сорбенты фирмы «Purolite» пористой структуры). Основные характеристики данных сорбентов представлены в таблице 1.

В качестве сырья для получения $\alpha$-амилазы использовался технический фер-

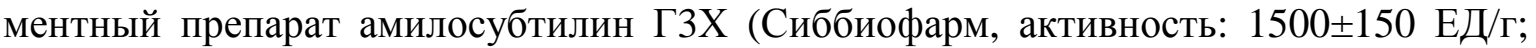

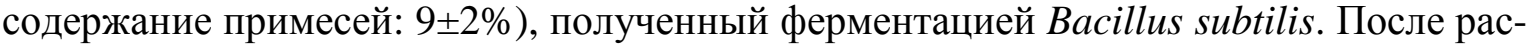
творения суспензию амилосубтилина центрифугировали на лабораторной центрифуге «ДАСТАН» ОПн-12; по окончании центрифугирования осадок отбрасывали, а супернатант использовали в экспериментальных целях.

Красовицкая и др. / Сорбционные и хроматографические процессы. 2017. Т. 17. № 4 
Таблица 1. Характеристика исследуемых сорбентов

\begin{tabular}{|c|c|c|c|c|}
\hline Сорбент & $\begin{array}{c}\text { Средний размер } \\
\text { зерна сорбента, } \\
\text { мм }\end{array}$ & $\begin{array}{c}\text { Коэффициент } \\
\text { набухания }\end{array}$ & $\begin{array}{c}\text { Внешний вид: фор- } \\
\text { ма зёрен, цвет }\end{array}$ & $\begin{array}{c}\text { Функциональные } \\
\text { группы }\end{array}$ \\
\hline MN-200 & $0.6-0.8$ & 1.3 & $\begin{array}{c}\text { Сферическая, } \\
\text { бежевый }\end{array}$ & - \\
\hline MN-202 & $0.6-0.8$ & 1.4 & $\begin{array}{c}\text { Сферическая, } \\
\text { тёмно-коричневый }\end{array}$ & - \\
\hline MN-500 & $0.6-0.8$ & 1.5 & $\begin{array}{c}\text { Сферическая, } \\
\text { чёрный }\end{array}$ & $\mathrm{SO}_{3}^{-}$ \\
\hline
\end{tabular}

Эксперименты по определению зависимости ёмкости сорбции от рН раствора, а также изучению равновесных параметров сорбции проводили в статических условиях при отношении навески сорбента (г) к объёму раствора $\left(\mathrm{cm}^{3}\right)$ 1:500, комнатной температуре и непрерывном перемешивании растворов на орбитальном шейкере CERTOMAT MOII в течение 24 ч. Для определения зависимости ёмкости сорбции от pH раствора в качестве исходного использовали раствор амилосубтилина с концентрацией общего белка $1.3 \mathrm{mг} / \mathrm{cm}^{3}$. Изотермы сорбции были получены при выбранном значении $\mathrm{pH}$ раствора $(\mathrm{pH}=4.8)$. Исходную и равновесную концентрацию общего белка в растворе определяли по методу Лоури [10]. Ёмкость сорбции (равновесную концентрацию общего белка в сорбенте Ссорб, мг/г) рассчитывали по балансовому соотношению. Коэффициент распределения сорбируемого вещества между фазами раствора и сорбента $\left(\mathrm{K}_{\mathrm{d}}, \mathrm{cm}^{3} / \Gamma\right)$ рассчитывали графическим методом при равновесной концентрации белка в растворе $2.8 \mathrm{мг} / \mathrm{cm}^{3}$.

Условия процесса десорбции были аналогичны условиям процесса сорбции. Десорбцию белка проводили в течение 1 ч раствором аммиака (pH 10-11) и смесью раствора аммиака с этанолом (концентрация этанола в растворе $30 \%$ ). По окончании процесса определяли концентрацию общего белка в растворе и рассчитывали выход на стадии десорбции в процентах (\%).

Для изучения процесса сорбции в динамических условиях использовали лабораторную колонку $\mathrm{d} \times \mathrm{H}=0.7 \times 40 \mathrm{~cm}$. В качестве исходного раствора был выбран раствор амилосубтилина с концентрацией общего белка $1.3 \mathrm{мг} / \mathrm{cm}^{3}$. Сорбцию и промывку сорбента проводили при рН 4.8, десорбцию при рН 10-11 (элюент - раствор аммиака). На протяжении всего процесса сорбции и десорбции отбирали фракции раствора на выходе из колонки и определяли в них концентрацию общего белка. При десорбции с катионита MN-500 в пробах с наибольшей концентрацией общего белка определяли специфическую активность фермента $\alpha$-амилазы по субстрату (крахмал), применяя модифицированный метод Рухлядевой [11]. На основании экспериментальных данных строили выходные кривые в относительных единицах:

$$
\frac{A_{i}}{A_{o}}=f\left(\frac{V_{i}-V_{o}}{V_{K}}\right) \quad \frac{c_{i}}{c_{o}}=f\left(\frac{V_{i}-V_{o}}{V_{K}}\right),
$$

где $\mathrm{A}_{\mathrm{i}}$ - ферментативная активность в пробе, ЕД/см${ }^{3} ; \mathrm{A}_{0}$ - ферментативная актив-

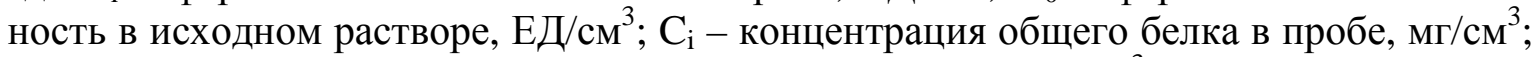

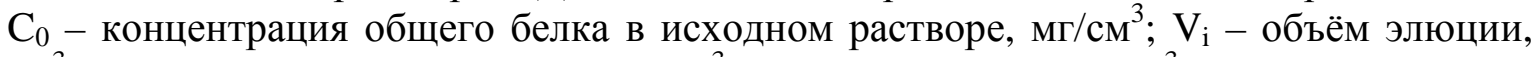
$\mathrm{cm}^{3} ; \mathrm{V}_{0}-$ свободный объём колонки, $\mathrm{cm}^{3} ; \mathrm{V}_{\text {к }}$ объём колонки, $\mathrm{cm}^{3}$.

Математическую обработку результатов исследований проводили в соответствии с методиками, изложенными в [10]. В качестве меры разброса значений от средней величины применяли выборочное среднеквадратичное отклонение единичного наблюдения. Уровень достоверности полученных результатов составлял не ниже $95 \%$.

Красовицкая и др. / Сорбционные и хроматографические процессы. 2017. Т. 17. № 4 


\section{Обсуждение результатов}

На первом этапе были подобраны условия проведения процесса сорбции. Результаты исследования показали, что зависимость ёмкости сорбции от рН (рис. 1) для молекулярных сорбентов MN-200 и MN-202 почти не наблюдается. Для сульфокатионообменника MN-500 зависимость ярко выражена, наибольшие значения ёмкости сорбции наблюдаются при рН 4-5. В связи с этим для проведения процесса сорбции выбрано значение $\mathrm{pH} 4.8$ - значение, близкое к изоэлектрической точке $\alpha$ амилазы.

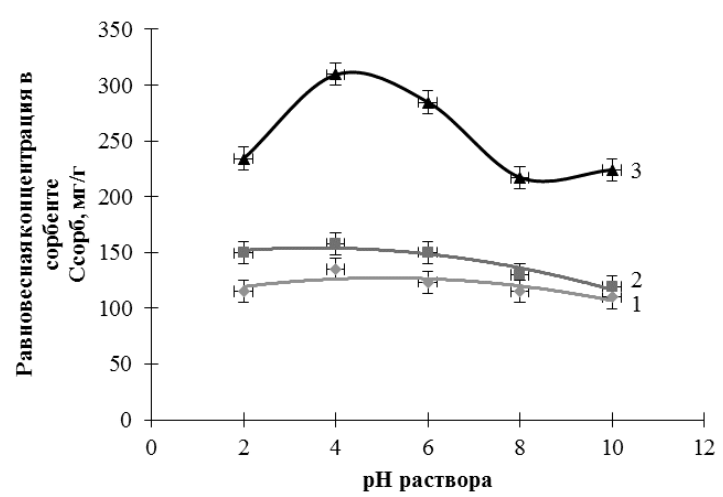

Рис. 1. Зависимость ёмкости сорбции $\alpha$ амилазы из раствора амилосубтилина от pH на сорбентах: 1) MN-200; 2) MN-202; 3) $\mathrm{MN}-500$

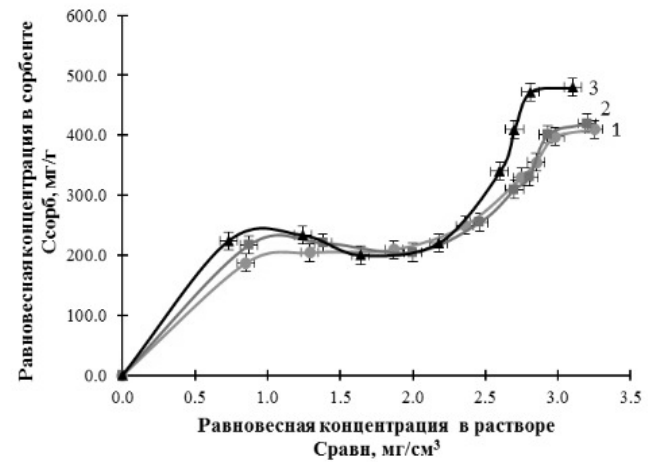

Рис. 2. Изотермы сорбции $\alpha$-амилазы из раствора амилосубтилина на сорбентаx: 1) MN-200; 2) MN-202; 3) MN-500

Вторым этапом было исследование равновесных параметров процесса сорбции $\alpha$-амилазы на сорбентах MN-200, MN-202, MN-500. Сорбцию проводили при различных концентрациях растворов амилосубтилина в статических условиях. На основании экспериментальных данных были построены изотермы сорбции, представленные на рис. 2. Полученные значения коэффициентов распределения приведены в таблице 2.

Таблица 2. Значения коэффициентов распределения и выход белка на стадии десорбции в статических условиях

\begin{tabular}{|c|c|c|c|}
\hline Сорбент & $\begin{array}{c}\text { Коэффициент } \\
\text { распределения } \\
\mathrm{K}_{\mathrm{d}}, \mathrm{cm}^{3} / \Gamma\end{array}$ & $\begin{array}{c}\text { Выход белка на стадии } \\
\text { десорбции (десорбция } \\
\text { раствором аммиака, } \mathrm{pH} \\
10-11), \%\end{array}$ & $\begin{array}{c}\text { Выход белка на стадии десорб- } \\
\text { ции (десорбция раствором ам- } \\
\text { миака и спирта в количестве } \\
30 \%), \%\end{array}$ \\
\hline $\mathrm{MN}-200$ & $120 \pm 0.5$ & $53 \pm 0.5$ & $87 \pm 0.5$ \\
\hline $\mathrm{MN}-202$ & $125 \pm 0.5$ & $49 \pm 0.5$ & $70 \pm 0.5$ \\
\hline $\mathrm{MN}-500$ & $169 \pm 0.5$ & $73 \pm 0.5$ & $6 \pm 0.5$ \\
\hline
\end{tabular}

Изотермы сорбции на исследуемых сорбентах имеют вид изотерм БЭТ, что говорит, с одной стороны, об упорядоченности сорбционных центров и статистическом распределении молекул белка на зерне сорбента, с другой стороны, о присутствии капиллярного эффекта. В соответствии с расчётными данными (табл. 2) можно сделать вывод о том, что процесс сорбции $\alpha$-амилазы протекает с наибольшей избирательностью на сульфокатионообменнике MN-500, о чём свидетельствует более высокий коэффициент распределения, чем у молекулярных сорбентов MN-200 и MN-202.

Показано, что при десорбции раствором аммиака выход для сорбентов MN200 и MN-202 невысок: десорбировалось около 50\% белка. Низкую степень десорб- 
ции можно объяснить высокой гидрофобностью матрицы исследуемых сорбентов. Следовательно, необходимо использование раствора аммиака с добавлением органического растворителя. В качестве такого растворителя в работе использовался этанол. Из табл. 2 видно, что при использовании этанола выход на стадии десорбции для MN-200 и MN-202 повышался примерно в 1.5 раза, а для сульфокатионообменника MN-500 оставался на прежнем уровне, при этом достаточно высоком, что может объясняться меньшим влиянием гидрофобности матрицы ионообменника $\mathrm{MN}$ 500 .

При сорбции ферментов, как правило, наблюдается внутридиффузионная кинетика и связанная с ней неравновесная динамика сорбции. Известно, что наибольшая эффективность сорбционно-хроматографического процесса достигается при регулярном режиме. Исследования процесса сорбции $\alpha$-амилазы в динамических условиях на сорбентах MN-200, MN-202 и MN-500 проводили при скорости пропускания раствора $1.7 * 10^{-4} \mathrm{~m} / \mathrm{c}$ (десорбции - при скорости $0.8 * 10^{-4} \mathrm{M} / \mathrm{c}$ ). Для оценки режима неравновесного процесса определяли критерий регулярности $\lambda$, который является одним из параметров эффективности колонки [12].

В соответствии с экспериментальными данными получены следующие выходные кривые сорбции: рис. 3.

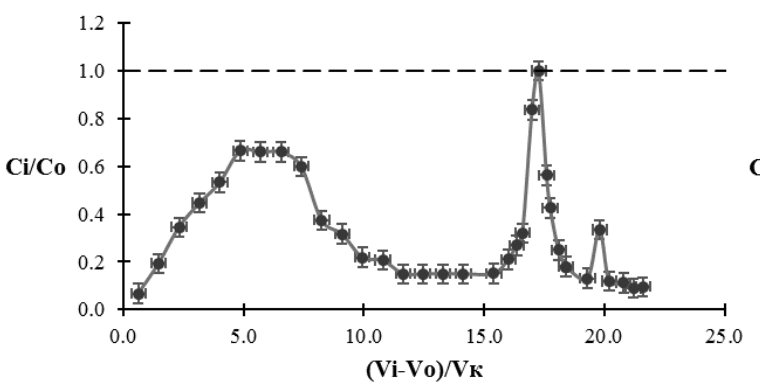

a)

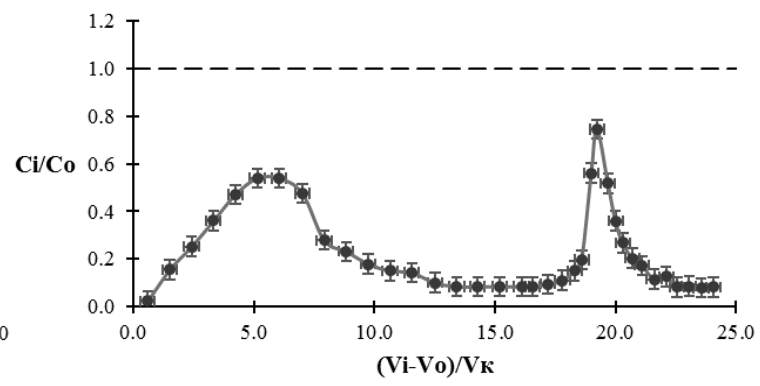

б)

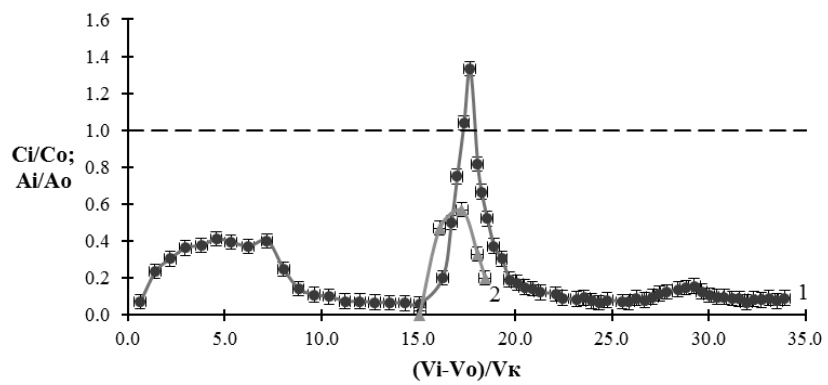

B)

Рис. 3. Выходные кривые сорбции, промывки и десорбции $\alpha$-амилазы на сорбентах: а) MN-200; б) MN-202; в) MN-500: 1 - относительная концентрация общего белка $\left(\frac{c_{i}}{c_{0}}\right), 2$ - относительная ферментативная активность $\alpha$-амилазы $\left(\frac{A_{i}}{A_{0}}\right)$

Режим сорбции является регулярным при $\lambda>0.35$, и нерегулярным при $\lambda<0.35$. Расчётные критерии $\lambda$ для сорбентов MN-200, MN-202 и MN-500 при заданной скорости сорбции составили соответственно: $0.31 ; 0.32$; 0.44 . Таким образом, регулярный режим достигается только при сорбции $\alpha$-амилазы на сульфокатионообменнике MN-500.

Выход на стадии десорбции $\alpha$-амилазы с сорбентов MN-200, MN-202 и MN500 составили соответственно: $50 \pm 0.5 \% ; 36 \pm 0.5 \% ; 62 \pm 0.5 \%$. Из рисунка 3 видно, что 
при десорбции на катионообменнике MN-500 с использованием раствора аммиака в качестве элюента происходит концентрирование по общему белку и сохраняется активность фермента. На сорбентах MN-200 и MN-202 концентрирования по общему белку не наблюдается, что может быть связано с высокой гидрофобностью их матрицы, следовательно, для более полной десорбции необходимо использовать раствор аммиака с добавлением этанола.

\section{Заключение}

Получены изотермы сорбции $\alpha$-амилазы из раствора амилосубтилина на сорбентах MN-200, MN-202 и MN-500, имеющих полистирольную структуру. Изотермы сорбции имеют вид изотерм БЭТ, что говорит об упорядоченности сорбционных центров и статистическом распределении молекул белка на зерне сорбента. Наибольшей избирательностью обладает сульфокатионообменник $\mathrm{MN}-500\left(\mathrm{~K}_{\mathrm{d}}=169 \pm 0.5\right.$ $\left.\mathrm{cm}^{3} / \Gamma\right)$. Анализ процесса десорбции $\alpha$-амилазы показал, что для неионогенных сорбентов MN-200 и MN-202 необходимо использование раствора аммиака с добавлением органического растворителя (этанола). При этом выход на стадии десорбции увеличивается в 1.5 раза и составляет $70-87 \%$. На эффективность десорбции $\alpha-$ амилазы с катионообменника MN-500 добавление органического растворителя не оказывало влияния - выход составил около $70 \%$.

Кинетико-динамический анализ процесса сорбции $\alpha$-амилазы на сорбентах MN-200, MN-202 и MN-500 по критериальному параметру $\lambda$ показал, что регулярный режим достигается только при сорбции на сульфокатионообменнике MN-500 $(\lambda=0.44)$. Для MN-500 получен наиболее высокий выход на стадии десорбции $\alpha-$ амилазы, при этом наблюдался эффект концентрирования.

Таким образом, сульфокатионообменник MN-500 может быть рекомендован для предварительной хроматографической очистки $\alpha$-амилазы Bacillus subtilis при получении комплексного препарата, сочетающего свойства ферментного препарата и энтеросорбента.

Авторы благодарят доктора химических наук, профессора В. А. Даванкова, заведующего лабораторией стереохимии сорбиионных процессов ИНЭОС РАН за любезное предоставление сорбентов и за помощь, оказанную в процессе работь.

\section{Список литературы}

1. Шифрин О.С. // Доктор. Ру. 2010. №5(56). C. 60-63.

2. Рачкова Н.С., Хавкин А.И. // Трудныци паииент. 2012. Т. 10. №2-3. С. 41-44.

3. Зинченко Л.Н., Кравцова А.Г., Орешина И.А. // Вестник Приднестровского университета. Сер.: Медико-биологические и химические науки. 2015. №2(50). С. 32-37.

4. Цюрупа М.П. Дисс. д-р. хим. наук. Москва. 1985. $427 \mathrm{c.}$

5. Царенко О.В. Дисс. канд. биол. наук. Санкт-Петербург. 2000. 125 с.

6. Грачева И.М. Технология ферментных препаратов. Москва, Агропромиздат, 1987. $335 \mathrm{c}$.

7. Григорьева Е.П. Дисс. канд. биол. наук. Санкт-Петербург. 2001. 142 с.
8. Красовицкая И.А. // «Молодая фармация - потенциал будущего», Фармация, сборник материалов VI Всероссийской научной конференции студентов и аспирантов с международным участием. 25-26 апреля 2016 г. Санкт-Петербург. 2016. С. 351-353.

9. Шкутина И.В., Стоянова О.Ф., Селеменев В.Ф., Бутырская Е.В. и др. // Химикофармачевтический журнал. 2009. Т. 43. № 9. C. 50-52.

10.Государственная фармакопея РФ XIII издание. Москва. 2015. Т. 1. 1468 с.

11.Рухлядева А.П., Полыгалина Г.В. Методы определения активности гидролитических ферментов. Москва. Легкая и пищевая пр-ть. 1981. 288 с. 
12.Сальникова С.А. Дисс. канд. фармацевт. наук. Санкт-Петербург. 2014. 147 с.

\section{References}

1. Shifrin O.S., Doktor. Ru, 2010, No 5(56), pp. 60-63.

2. Rachkova N.S., Khavkin A.I., Trudnyi patsient, 2012, Vol. 10, No 2-3, pp. 41-44.

3. Zinchenko L.N., Kravtsova A.G., Oreshina

I.A., Vestnik Pridnestrovskogo universiteta. Ser.: Mediko-biologicheskie i khimicheskie nau$k i, 2015$, No 2(50), pp. 32-37

4. Tsyurupa M.P. Diss. d-r. chem. nauk. Moscow, 1985, $427 \mathrm{p}$.

5. Tsarenko O.V. Diss. kand. biol. nauk. St. Petersburg, 2000, $125 \mathrm{p}$.

6. Gracheva I.M. Tekhnologiya fermentnykh preparatov. Moscow, Agropromizdat Publ., 1987, $335 \mathrm{p}$.

7. Grigor'eva E.P. Diss. kand. biol. nauk. St. Petersburg, 2001, 142 p.

8. Krasovitskaya I.A. «Molodaya farmatsiya - potentsial budushchego», Farmatsiya, Sbornik materialov VI Vserossiiskoi nauchnoi konferentsii studentov $\mathrm{i}$ aspirantov s mezhdunarodnym uchastiem, April 25-26, 2016, St. Petersburg, 2016, pp. 351-353

9. Shkutina I.V., Stoyanova O.F., Selemenev V.F., Butyrskaya E.V. et al., Khimikofarmatsevticheskii zhurnal, 2009, Vol. 43, No 9, pp. 50-52.

10. State pharmacopeia RF XIII Edition. Moscow, 2015, Vol. 1, 1468 p.

11.Rukhlyadeva A.P., Polygalina G.V. Metody opredeleniya aktivnosti gidroliticheskikh fermentov. Moscow, Legkaya i pishchevaya prt' Publ., 1981, 288 p.

12. Sal'nikova S.A. Diss. kand. farmatsevt. nauk. St. Petersburg, 2014, 147 p.

Красовицкая Ирина Александровна - магистрант, кафедра биотехнологии, СанктПетербургская государственная химикофармацевтическая академия, Санкт-Петербург

Глазова Наталья Владимировна - доцент кафедры биотехнологии, к.х.н., СанктПетербургская государственная химикофармацевтическая академия, Санкт-Петербург

Котова Наталия Владимировна - доцент кафедры биотехнологии, к.х.н., СанктПетербургская государственная химикофармацевтическая академия, Санкт-Петербург
Krasovitskaya Irina A. - master student, department of biotechnology, St. Petersburg State Chemical Pharmaceutical Academy, St. Petersburg, e-mail: krasovizkaya.irina@pharminnotech.com

Glazova Natal'ya V. - Ph.D. (chemistry), associate prof., department of biotechnology, St. Petersburg State Chemical Pharmaceutical Academy, St. Petersburg, e-mail: nvglazova13@mail.ru

Kotova Nataliya V. - Ph.D. (chemistry), associate prof., department of biotechnology, St. Petersburg State Chemical Pharmaceutical Academy, St. Petersburg, e-mail: kotntvl@mail.ru 